\title{
Synthesis of poly(pyridyl)porphyrins by Heck and Sonogashira cross-coupling reactions
}

\section{Bernardo A. Iglesias ${ }^{\star}$, Henrique E. Toma and Koiti Araki}

Universidade de São Paulo, Instituto de Química, Av. Prof. Lineu Preste 748, CEP 05508-900, São Paulo,

$$
S P \text {, Brazil. }
$$

*Iglesias@iq.usp.br

Keywords: Porphyrins, Pd catalysis, Cross-coupling reactions

\section{INTRODUCTION}

Porphyrins are an interesting class of heteroaromatic 18 m-electron aromatic macrocycles that have found wide applications in many fields, including biologic systems, medicine, catalysis and materials ${ }^{1}$. Such applications explore their optical, photochemical, photoelectrochemical, catalytic, binding and electrochemical properties ${ }^{2,3}$.

In this work, we report the synthesis and spectroscopic characterization ( ${ }^{1} \mathrm{H}$ NMR, ESI-MS and UV-vis) of a new porphyrin substituted with vinilpyridine (1) and ethynyl-terpyridine (2).

\section{RESULTS AND DISCUSSION}

The meso-vinylpyridyl porphyrin (1) was obtained in DMF by the reaction of the brominated precursor and 3 equivalent of 4-vinylpyridine, in the presence of $\mathrm{Pd}(\mathrm{OAc})_{2} / \mathrm{PPh}_{3}$ as catalyst, and triethylamine as non-coordinant base (Scheme 1).
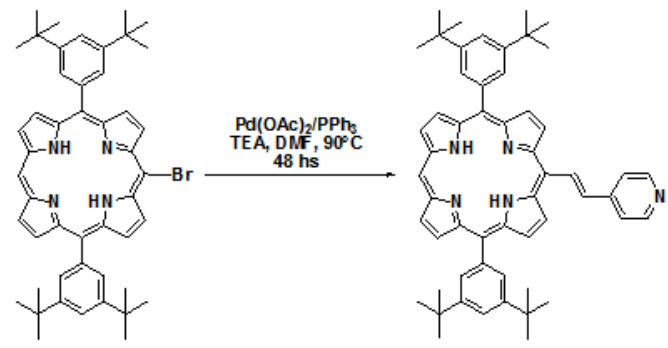

(1)

Scheme 1. Scheme of the synthesis of meso-(4vinylpyridyl)porphyrin (1).

The meso-ethynyl(terpyridyl) porphyrin (2) was obtained in DMF by the reaction of the mesobrominated precursor and 2 equivalent of 4$14^{\text {th }}$ Brazilian Meeting on Organic Synthesis $-14^{\text {th }}$ BMOS - September 01-05, 2011-Brasilia, Brazil ethynylterpyridine, in the presence of $\left[\mathrm{Pd}\left(\mathrm{PPh}_{3}\right)_{2} \mathrm{Cl}_{2}\right]$ and Cul as catalyst, and iso-propylamine as noncoordinant base (Scheme 2).
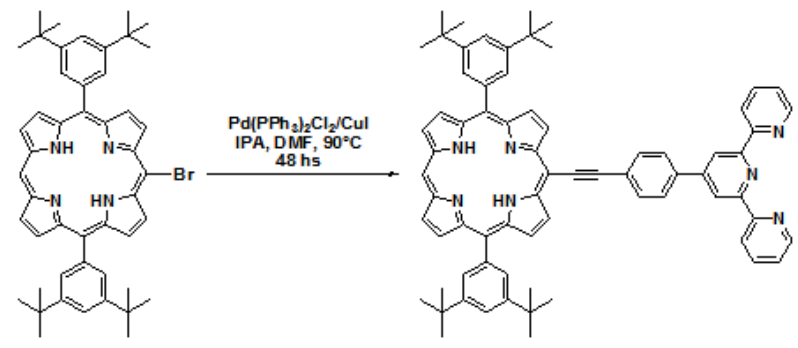

Scheme 2. Scheme of the synthesis of meso-(4ethynylterpyridyl)porphyrin (2).

\section{CONCLUSION}

This class of compound presents significant interest in supramolecular and coordination chemistry, as well as molecular nanoscience and molecular switches. Further studies are on the way to evaluate the photochemical and the photophysical properties of this new series of porphyrins with stilbene-pyridine and ethynyl-terpyridine substituents directly bond at the meso-position.

\section{ACKNOWLEDGEMENTS}

Were thanks the FAPESP and CNPq for the financial support.

\section{REFERENCES}

${ }^{1}$ Kadish, K.M.; Smith, K.M.; Guilard, R.; The Porphyrin Handbook; Academic Press, San Diego, 2000-2003, vol.1-20.

${ }^{2}$ Setsune, J.; J. Porphyrins Phtalocyanines; 2004, 8, 93.

${ }^{3}$ Locos, O.B.; Arnold, D.P.; Org. Biomol. Chem.; 2006, 4, 902. 